\title{
Intratracheal Instillation of Keratinocyte Growth Factor Decreases Hyperoxia-induced Mortality in Rats
}

Ralph J. Panos, * Philip M. Bak, ${ }^{*}$ W. Scott Simonet, ${ }^{\star}$ Jeffrey S. Rubin, ${ }^{\S}$ and Lewis J. Smith*

* Pulmonary Divisions, Northwestern University Medical School and Veterans Administration Lakeside Medical Center, Chicago, Illinois 60611; ${ }^{\ddagger}$ Amgen, Inc., Thousand Oaks, California 91320; and ${ }^{\S}$ Laboratory of Cellular and Molecular Biology, National Cancer Institute, National Institutes of Health, Bethesda, Maryland 20892

\begin{abstract}
Alveolar type II cell proliferation occurs after many forms of lung injury and is thought to play a critical role in alveolar epithelial repair. Keratinocyte growth factor/fibroblast growth factor 7 (KGF) has been shown to promote alveolar type II cell growth in primary culture and alveolar epithelial hyperplasia in vivo. In this study, we used immunohistochemical analysis to determine the intrapulmonary distribution and cellular localization of recombinant human KGF (rhKGF) instilled into the trachea of rats. $6 \mathrm{~h}$ after administration, immunoreactive KGF was observed within the lung parenchyma and along alveolar epithelial cell membranes. By 18-24 h, KGF was detected intracellularly in alveolar epithelial cells and intraalveolar macrophages. Immunoreactive KGF was not demonstrable $48 \mathrm{~h}$ after delivery or in lung sections from PBS-treated animals. Intratracheal instillation of $5 \mathrm{mg} / \mathrm{kg}$ rhKGF stimulated a marked, timedependent increase in the alveolar type II cell specific labeling index to a maximum level of $33 \pm 3 \% 48 \mathrm{~h}$ after rhKGF administration compared with $1.3 \pm 0.3 \%$ after PBS instillation. In addition, this increase in type II cell proliferation in vivo was documented by flow cytometric analysis of isolated type II cells which revealed a nearly fivefold increase in the proportion of cells traversing through the $S$ and G2/ $M$ phases of the cell cycle. To test the hypothesis that KGFs effects on type II cells in vivo might affect the response to lung injury, rats were treated with rhKGF and exposed to hyperoxia. Animals that received 1 or $5 \mathrm{mg} / \mathrm{kg}$ rhKGF exhibited dramatically reduced mortality $(P<0.001$, for both doses). Survival for animals treated with $0.1 \mathrm{mg} / \mathrm{kg}$ rhKGF was not significantly different from either untreated rats or animals treated with heat-denatured rhKGF. The lungs of rhKGF-treated animals that survived hyperoxia exposure had minimal hemorrhage and no exudate within the intraalveolar space. These experiments established that intratracheal administration of rhKGF stimulated alveolar type II cell proliferation in vivo and reduced hyperoxia-
\end{abstract}

Address correspondence to Ralph J. Panos, MD, Pulmonary Division, Northwestern University Medical School, Room 777, Passavant Pavilion, 303 East Superior Street, Chicago, IL 60611. Phone: 312-503-0199; FAX: 312-908-4650.

Received for publication 10 March 1995 and accepted in revised form 6 July 1995.

The Journal of Clinical Investigation, Inc.

Volume 96, October 1995, 2026-2033 induced lung injury in rats. Directed delivery of KGF to the lungs may provide a therapeutic strategy to preserve or restore the alveolar epithelium during exposure to hyperoxia or other injurious agents. (J. Clin. Invest. 1995. 96:2026-2033.) Key words: alveolar type II cell • keratinocyte growth factor $\bullet$ proliferation $\bullet$ oxygen

\section{Introduction}

Alveolar epithelial cell damage occurs universally in common respiratory illnesses such as the adult and infant respiratory distress syndromes as well as radiation- and chemotherapyinduced lung injury. Evans, Witschi, and others (1-5) have proposed that the sequence of events in alveolar epithelial injury and repair is $(a)$ injury and loss of type I cells, denuding the alveolar epithelial basement membrane; $(b)$ proliferation of alveolar type II cells, generating a hypertrophic, hyperplastic epithelium; and (c) differentiation of type II cells into type I cells, restoring the integrity and gas exchange function of the alveolar epithelium. If type II cell proliferation and differentiation are impaired by severe or sustained lung injury, obliteration of the alveolar space may occur by apposition of the alveolar walls or accumulation of mesenchymal cells and granulation tissue within the intraalveolar space (6). Fibrosis ensues, alveolar gas exchange units are lost, and lung function decreases. Although alveolar type II cell proliferation has been described after many forms of lung injury and appears to be a critical factor in alveolar epithelial repair and maintenance of pulmonary gas exchange function, the regulation of pulmonary healing processes is not well understood.

Keratinocyte growth factor/fibroblast growth factor-7 (KGF/FGF-7 $)^{1}$ was identified as a fibroblast-derived, heparinbinding mitogen with activity in vitro restricted to epithelial cells $(7,8)$. The unique target cell specificity was a consequence of the KGF receptor, a splice variant of FGF receptor 2 whose expression in cell lines was confined to epithelial cells (9). These observations led to the hypothesis that KGF functioned as a paracrine mediator of mesenchymal-epithelial cell interactions affecting growth and development. This concept was supported by a series of subsequent experiments designed to investigate KGF expression and activity in whole animals and organ culture systems. In situ hybridization analysis of embryonic tissue localized KGF transcripts primarily to the stromal compartment of epithelial tissues, whereas KGF recep-

1. Abbreviations used in this paper: BrdUrd, bromodeoxyuridine; KGF, keratinocyte growth factor; rhKGF, recombinant human KGF. 
tor expression was detected in the adjacent epithelial cells (1012). KGF expression was induced by testosterone in mesenchymal cells of the neonatal mouse seminal vesicle, where KGF was shown to mediate androgen-dependent branching of the glandular structures (13). Systemic administration of recombinant human KGF (rhKGF) to adult rats specifically promoted epithelial hyperplasia in the lung, mammary gland, liver, and throughout much of the gastrointestinal tract (14-17). In addition, topical administration of rhKGF stimulated epidermal regeneration in different models of skin injury $(18,19)$. Targeting expression of a dominant negative KGF receptor mutant to skin resulted in epidermal atrophy and delayed reepithelialization of skin wounds (20). These latter findings were consistent with an earlier observation of dramatic KGF mRNA induction after the creation of full-thickness wounds in mouse skin (21). Thus, the data strongly suggest that KGF participates in epithelial growth and repair processes during development and in the adult.

KGF appears to have a particularly important role as a mediator of epithelial-mesenchymal cell interactions within the lung. KGF was isolated from the conditioned media of both fetal and adult lung fibroblasts in culture $(7,22)$ and was shown to stimulate alveolar type II cell proliferation in vitro (22). Transcripts for KGF and KGF receptor were detected in lung tissue from embryonic and adult animals $(10-12,14)$. Branching morphogenesis and epithelial cell differentiation were blocked in transgenic mice expressing a dominant negative KGF receptor in alveolar type II cells (23). These animals died immediately after birth due to the failure of lung parenchymal development. Consistent with this result, intratracheal instillation of KGF in normal rats stimulated alveolar epithelial hyperplasia and expression of proliferating cell nuclear antigen (14).

Because of its activity in cutaneous wound healing and alveolar type II cell proliferation, KGF may play an important role in pulmonary repair. As a first step in testing the effect of rhKGF, we used immunohistochemical analysis to evaluate the distribution and cellular localization of immunoreactive KGF delivered to the lung by intratracheal instillation. The proliferative effect of rhKGF on alveolar type II cells was quantitated by double-label immunohistochemistry and flow cytometric cell cycle analysis. Finally, to determine whether rhKGF administration would alter the response to lung injury, rats were given rhKGF by intratracheal instillation and exposed to hyperoxia. rhKGF caused a highly significant, dose-dependent reduction in hyperoxia-induced lung injury and death.

\section{Methods}

rhKGF instillation. rhKGF was expressed and purified as described previously $(14,24)$. Adult male Sprague-Dawley rats weighing 150 250 grams were given rhKGF by intratracheal instillation (25). Briefly, rats were anesthetized with $87 \mathrm{mg} / \mathrm{kg}$ ketamine and $13 \mathrm{mg} / \mathrm{kg}$ xylazine by intraperitoneal injection. Once stage IV anesthesia was achieved, rats were placed in a supine position and orally intubated with an 18gauge catheter under direct vision using a fiberoptic light source. Correct position of the catheter was ascertained by insufflation and observation of the chest and abdomen. Sedation was allowed to lighten slightly and then $3 \mathrm{ml}$ of air and rhKGF in $0.6 \mathrm{ml}$ of PBS were instilled via the endotracheal catheter with the rat in a vertical position. The catheter was removed when the animal awakened from anesthesia. Control animals were given $0.6 \mathrm{ml}$ of PBS by intratracheal instillation and were processed in the same manner as the rhKGF-treated animals.

Immunohistochemical detection of $K G F$. To verify that rhKGF was delivered to the lung parenchyma and to determine the time course of tissue availability of rhKGF administered by intratracheal instillation, rats were killed $6,18,24,48$, and $72 \mathrm{~h}$ after receiving $5 \mathrm{mg} / \mathrm{kg}$ rhKGF or PBS. The lungs were excised, fixed with $10 \%$ buffered formalin at $20 \mathrm{~cm} \mathrm{H}_{2} \mathrm{O}$ pressure, and embedded in paraffin. Sagittal 4- $\mu \mathrm{m}$ sections of the apical, middle, and basal portions of the left lung were incubated with $9 \mu \mathrm{g} / \mathrm{ml}$ of the IgG purified fraction of rabbit polyclonal antisera raised against a synthetic peptide corresponding to the carboxy-terminal sequence of hKGF (26). After washing in PBS, the slides were incubated with biotinylated goat anti-rabbit IgG (Vector Laboratories, Burlingame, CA), followed by streptavidin-alkaline phosphatase enzyme conjugate (Zymed Laboratories, South San Francisco, CA). After Sigma Fast ${ }^{\text {* }}$ fast red TR/naphthol AS-MX substrate reaction mixture (Sigma Immunochemicals, St. Louis, MO) was added, the reaction was monitored under the microscope and stopped when the desired staining intensity was reached. The slides were counterstained briefly in hematoxylin and mounted in aqueous mounting solution. Specificity of the reaction product was determined by substituting preimmune serum for the primary antibody or by incubating the purified IgG antibody $(9 \mu \mathrm{g} / \mathrm{ml})$ with $34 \mu \mathrm{g} / \mathrm{ml}$ of synthetic peptide overnight at $4^{\circ} \mathrm{C}$ before use in the immunohistochemistry protocol.

Alveolar type II cell specific labeling index. The alveolar type II cell specific labeling index was determined by double-label immunohistochemistry using antibodies directed against bromodeoxyuridine (BrdUrd) to detect cells undergoing DNA synthesis, and a murine monoclonal antibody, 3F9, to identify alveolar type II cells within the lung parenchyma (27). Either PBS or $5 \mathrm{mg} / \mathrm{kg}$ rhKGF was given by intratracheal instillation and the animals were killed $18,24,48$, or 72 $h$ later. To determine whether the effect of rhKGF on the alveolar type II cell specific labeling index was dose dependent, other animals received either 0.1 or $1.0 \mathrm{mg} / \mathrm{kg}$ rhKGF and were killed at $48 \mathrm{~h} .18 \mathrm{~h}$ before death, all rats received $100 \mathrm{mg} / \mathrm{kg}$ BrdUrd by intraperitoneal injection. The effect of rhKGF on type II cell proliferation during hyperoxia was determined by giving rats either PBS or $5 \mathrm{mg} / \mathrm{kg}$ rhKGF and exposing them to hyperoxia for $48 \mathrm{~h}$. The hyperoxia exposure was briefly interrupted ( $<15 \mathrm{~min}$ ) after $30 \mathrm{~h}$ for the administration of 100 $\mathrm{mg} / \mathrm{kg}$ BrdUrd by intraperitoneal injection.

The lungs were excised and fixed in $10 \%$ neutral buffered formalin at $20 \mathrm{~cm}$ of water pressure by intratracheal perfusion. Tissues were embedded in paraffin, and 4- $\mu \mathrm{m}$ sections were cut and mounted on 3aminopropyltriethoxysilane-coated slides. After the sections were air dried, deparaffinized, and rehydrated, they were incubated in $3 \%$ horse serum diluted in PBS for $30 \mathrm{~min}$ at room temperature. The slides were exposed overnight at $4^{\circ} \mathrm{C}$ to the $3 \mathrm{~F} 9$ hybridoma supernatant (a generous gift from York E. Miller, Denver, CO) diluted 1:300 in 3\% horse serum. The slides were then washed and incubated for $1 \mathrm{~h}$ at room temperature with biotinylated horse anti-mouse IgG (Vector Laboratories) diluted 1:200 in 3\% horse serum in PBS. After washing in $50 \mathrm{mM}$ Tris-buffered saline (TBS) ( $135 \mathrm{mM} \mathrm{NaCl}, 0.05 \mathrm{M}$ Tris, $\mathrm{pH} 7.4$ ), streptavidin-alkaline phosphatase conjugate (Zymed Laboratories) diluted 1:20 in TBS was added. The sections were incubated with the new fuchsin/naphthol AS-MX substrate reaction mixture (12.5 mg naphthol AS-MX phosphate [Sigma Immunochemicals], $25 \mathrm{ml} 0.05 \mathrm{M}$ Tris, pH 8.7, 0.125 $\mathrm{ml} 4 \%$ sodium nitrite, $0.05 \mathrm{ml} 5 \%$ new fuchsin [Sigma Immunochemicals] in $2 \mathrm{~N} \mathrm{HCl}$ ) and the reaction was monitored. When the desired intensity was reached, the slides were washed in $\mathrm{ddH}_{2} \mathrm{O}$. The sections were then incubated in $1 \% \mathrm{H}_{2} \mathrm{O}_{2}$ dissolved in $0.1 \%$ Triton $\mathrm{X}-100$ and washed in PBS. After incubation in $100 \mu \mathrm{g} / \mathrm{ml}$ pronase $\mathrm{E}$ (Sigma Immunochemicals $)$ in pronase buffer $\left(0.02 \mathrm{M}\right.$ Tris- $\mathrm{HCl}, 20 \mathrm{mM} \mathrm{CaCl}_{2}, \mathrm{pH}$ 7.6), the sections were rinsed with pronase buffer. To remove DNA binding proteins, the sections were incubated in ice cold $0.1 \mathrm{~N} \mathrm{HCl}$ for $10 \mathrm{~min}$. DNA was denatured by incubating the slides in $2 \mathrm{~N} \mathrm{HCl}$ for $30 \mathrm{~min}$ at $37^{\circ} \mathrm{C}$ and then the acid was neutralized with $0.1 \mathrm{M}$ borax, $\mathrm{pH}$ 8.5. The slides were then incubated with the anti-BrdUrd monoclonal antibody, Bu20a (Dako, Carpinteria, CA) diluted 1:50 in 3\% horse serum for $1 \mathrm{~h}$ at room temperature. After washing in PBS, horseradish peroxidase-conjugated goat anti-mouse IgG (Sigma Immunochemicals) diluted 1:75 in 3\% horse serum was added for $1 \mathrm{~h}$ at room temperature. The diaminobenzidine-peroxidase reaction product was intensified using nickel-silver enhancement (28). The reaction was monitored un- 

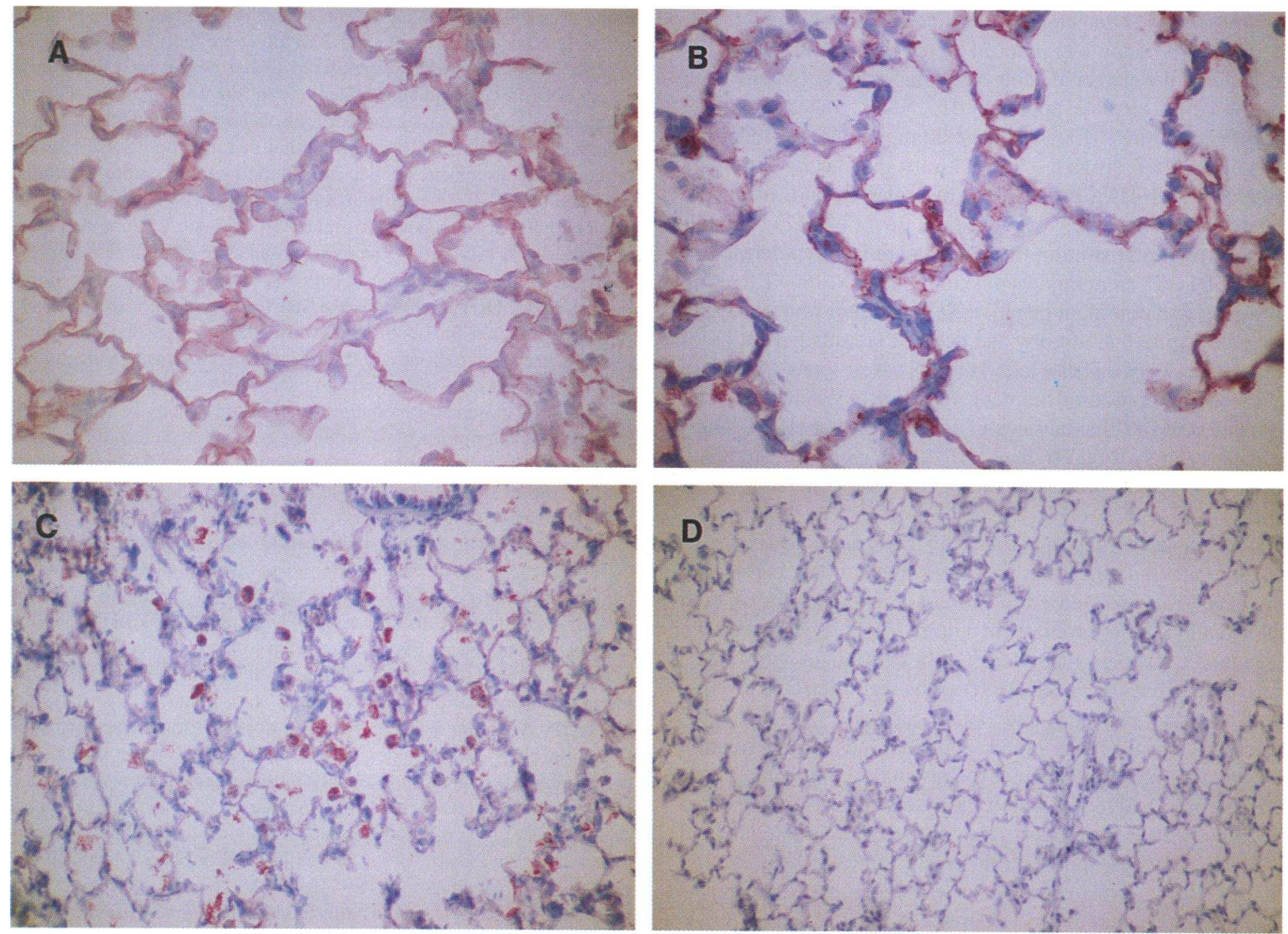

Figure 1. Immunohistochemical detection of KGF after intratracheal administration. Rats were given $5 \mathrm{mg} / \mathrm{kg}$ rhKGF and KGF immunodetection was performed as described in Methods. ( $A$ ) Immunoreactive KGF was detected within the alveolar interstitium $6 \mathrm{~h}$ after intratracheal instillation (original magnification of 400). (B) By $18 \mathrm{~h}$, KGF was located intracellularly within aiveolar epithelial cells and macrophages as well as in the interstitium (original magnification of 400). (C) Immunoreactive KGF was concentrated within intraalveolar mononuclear cells $24 \mathrm{~h}$ after intratracheal instillation (original magnification of 200). (D) When the antibody was incubated with synthetic peptide before use in the immunohistochemical protocol, no immunoreactive KGF was detected (original magnification of 200). KGF was not detectable in lung sections obtained 48 and $72 \mathrm{~h}$ after rhKGF administration or at any time point after PBS instillation (data not shown).

der the microscope and stopped when the desired intensification was achieved. The slides were counterstained with hematoxylin and mounted in $90 \%$ glycerol.

Type II cells were identified by a maroon apical reaction product on epithelial cells in the peripheral lung parenchyma, and proliferating cells were detected by black nuclear staining. The type II cell proliferation index was calculated as the number of double-labeled cells divided by the total number of type II cells. At least 400 type II cells were counted per section.

Flow cytometric cell cycle analysis of isolated alveolar type II cells. Type II cells were isolated from rats by elastase dissociation and differential adherence $48 \mathrm{~h}$ after the administration of either PBS or $5 \mathrm{mg} /$ $\mathrm{kg}$ rhKGF by intratracheal instillation (29). Cell viability was determined by vital dye exclusion and the purity of alveolar type II cells was assessed by the presence of intracytoplasmic inclusions (29). Alveolar type II cell purity was $>80 \%$ and cell viability was $>90 \%$ immediately after isolation. The freshly isolated cells were fixed in ice-cold $70 \%$ ethanol and then incubated with $1 \mathrm{mg} / \mathrm{ml}$ RNase A diluted in PBS at $37^{\circ} \mathrm{C}$ for $30 \mathrm{~min}$ and washed with PBS. They were then resuspended in $50 \mu \mathrm{g} / \mathrm{ml}$ propidium iodide in PBS for $30 \mathrm{~min}$. The cytokinetic status of the isolated type II cells was determined by measurement of the DNA distribution using flow cytometry as described previously (30).

Hyperoxia exposure. Hyperoxia exposures were performed as described previously (31-35). This protocol was reviewed and approved by the Animal Care and Use Committee, Lakeside Veterans Administration Hospital. Sprague-Dawley rats were exposed to $100 \%$ oxygen at 3 liters/min in an airtight chamber. Throughout the exposure, they had free access to water and food. Drierite $\left(\mathrm{CaSO}_{4}\right)$ was placed in the chamber to reduce the humidity and carbon dioxide was removed by adsorption to soda lime. Animals were carefully monitored four to five times daily for respiratory distress. Animals experiencing excessive labored breathing (a respiratory rate $>140$ breaths/min or gasping, extension of the neck, and adduction of the forelimbs in a posture of labored respiration, use of abdominal muscles to assist breathing, or gasping agonal breathing) were killed by administration of pentobarbital and exsanguination by transection of the abdominal aorta. Animals surviving for $120 \mathrm{~h}$ in hyperoxia were killed in the same manner and the lungs excised and fixed for histopathologic examination.

To determine the concentration-dependent effect of KGF on survival in hyperoxia, groups of animals were given $0.1,1$, or $5 \mathrm{mg} / \mathrm{kg}$ rhKGF by intratracheal instillation. Control animals received either $5 \mathrm{mg} / \mathrm{kg}$ rhKGF that had been heat denatured by boiling for $30 \mathrm{~min}$, which has been demonstrated to eliminate mitogenic activity in vitro $(7,22,24)$, or were not treated. Between 5 and 11 animals were treated in each group. Survival data were expressed using Kaplan-Meier product limit curves which were compared using the log rank test (36).

Antioxidant enzyme assays. Because the induction of antioxidant enzymes by cytokines has been shown to increase the survival of rats 

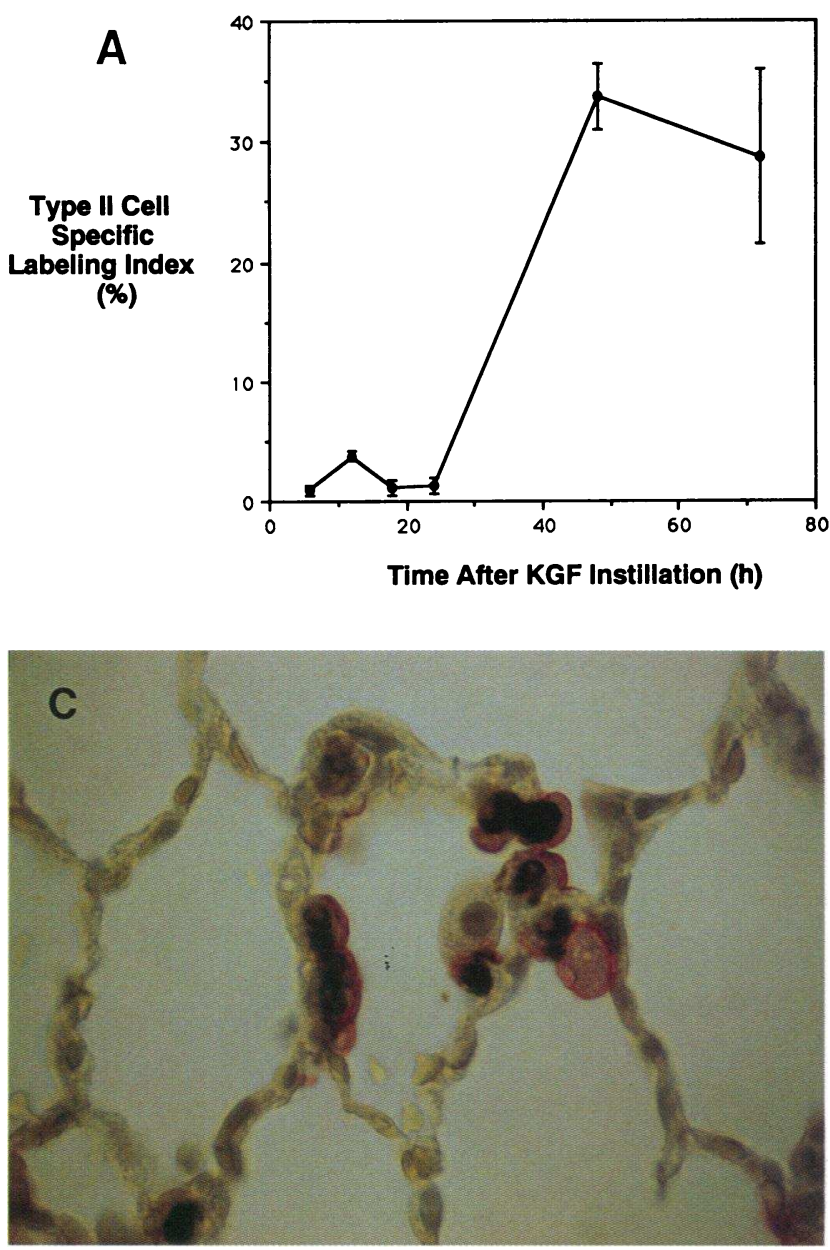

exposed to hyperoxia $(37,38)$, we measured whole lung superoxide dismutase (SOD), Mn SOD, Cu/Zn SOD, and catalase enzymatic activities after the intratracheal instillation of either PBS or $5 \mathrm{mg} / \mathrm{kg}$ rhKGF and exposure to room air or hyperoxia for $48 \mathrm{~h}$. Lungs were homogenized for $60 \mathrm{~s}$ in cold hypotonic buffer $(5 \mathrm{mM}$ potassium phosphate, $\mathrm{pH} 7.4$ ) using a weight (gram) to volume (milliliter) ratio of 1:25. The homogenate was centrifuged at $500 \mathrm{~g}$ for $10 \mathrm{~min}$, the pellet was discarded, and the supernatant was centrifuged at $20,000 \mathrm{~g}$ for $10 \mathrm{~min}$. Aliquots of the supernatant were assayed for protein, SOD, and catalase. Protein was quantitated by the method of Lowry and co-workers (39). SOD and catalase were measured spectrophotometrically $(31,40)$. Data are expressed as the mean $\pm \mathrm{SE}$ and were compared using a two-tailed $t$ test (Stat View).

\section{Results}

Immunoreactive KGF is detectable within the lung parenchyma after intratracheal instillation. Immunoreactive KGF protein was readily detected in rat lung sections obtained from animals $6 \mathrm{~h}$ after instillation of $5 \mathrm{mg} / \mathrm{kg}$ rhKGF (Fig. $1 A$ ). KGF was present within the lung parenchyma, suggesting that the instilled rhKGF was distributed distally into the intraalveolar spaces after injection into the trachea. A strong reaction product was homogeneously localized to the interstitium and both cuboidal and flattened alveolar epithelial cell membranes. By 18-24 h, the immunoreactive protein was more heterogeneously distributed along the basement membrane and was also found within alveolar epithelial cells and intraalveolar cells (Fig. 1, $B$ and $C)$. The latter probably were macrophages engaged in the

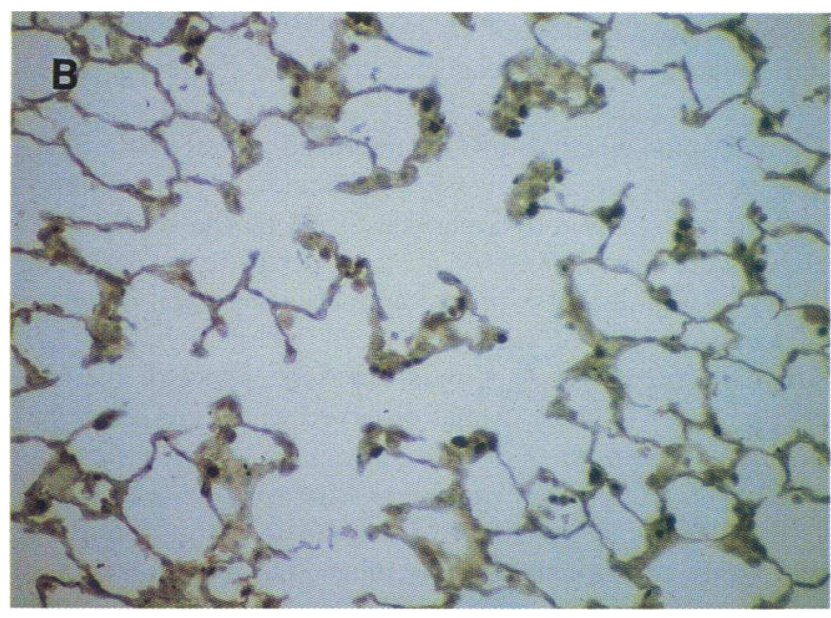

Figure 2. (A) Time-dependent increase in the alveolar type II cell specific labeling index after the intratracheal instillation of $5 \mathrm{mg} / \mathrm{kg} \mathrm{rhKGF}$. Double-label immunohistochemistry was performed as described in Methods. The alveolar type II cell labeling index was calculated as the number of double-labeled cells divided by the total number of type II cells. The type II cell labeling index was $1.3 \pm 0.3 \%$ after the intratracheal instillation of PBS and did not change with time. $(B)$ Light micrograph demonstrating the double-label immunohistochemical detection of proliferating alveolar type II cells in lung sections obtained from rats $48 \mathrm{~h}$ after intratracheal rhKGF instillation. Alveolar type II cells were detected using the 3F9 antibody and are identified by maroon apical staining, while proliferating cells that incorporated BrdUrd were detected using the Bu20a antibody and are recognized by black nuclear staining. Clusters of proliferating alveolar epithelial cells are present in the corners of the alveoli (original magnification of 200). (C) The doublelabel immunohistochemical technique identifies proliferating alveolar type II cells and discriminates alveolar epithelial cells from mononuclear cells within the intraalveolar space (original magnification of 1,000).

phagocytic clearance of instilled rhKGF. The staining intensity was decreased compared with earlier time points. No immunoreactive KGF was detected $48-72 \mathrm{~h}$ after rhKGF administration. In PBS-treated animals, no KGF was observed. When either preimmune serum or peptide-absorbed antisera were used in the immunohistochemistry protocol, no immunoreactive KGF was detected in lung tissue sections from rhKGF-treated animals (Fig. $1 D)$.

rhKGF administration stimulates type II cell proliferation in vivo. Intratracheal administration of $5 \mathrm{mg} / \mathrm{kg}$ rhKGF induced a time-dependent increase in type II cell proliferation (Fig. 2). No effect on the type II cell labeling index was observed up to $24 \mathrm{~h}$ after instillation. However, at $48 \mathrm{~h}$, there was a marked increase in type II cell proliferation with a maximal alveolar type II cell labeling index of $33 \pm 3 \%$ that decreased slightly to $28.8 \pm 7 \%$ at $72 \mathrm{~h}$. In PBS-treated animals the type II cell labeling index was $1.3 \pm 0.3 \%$ and did not vary with time after instillation. To determine whether the proliferative response to rhKGF was dose dependent, rats were given either 0.1 or 1.0 $\mathrm{mg} / \mathrm{kg}$ rhKGF by intratracheal instillation and killed at $48 \mathrm{~h}$. The type II cell labeling index was $16.4 \pm 1.1 \%$ for $0.1 \mathrm{mg} / \mathrm{kg}$ and $24.4 \pm 2.4 \%$ for $1.0 \mathrm{mg} / \mathrm{kg}$. In addition, alveolar type II cells were isolated from rats by elastase dissociation and differential adherence $48 \mathrm{~h}$ after the administration of $5 \mathrm{mg} / \mathrm{kg}$ rhKGF and cell cycle analysis performed by flow cytometry $(29,30)$. The percentage of cells in the proliferative phases of the cell cycle, $\mathrm{S}$ and $\mathrm{G} 2 / \mathrm{M}$, increased from $<5 \%$ in PBS-treated animals to $23 \pm 2 \%$ after rhKGF administration. Thus, these studies pro- 
vided quantitative evidence that intratracheal administration of rhKGF induced a dose-dependent increase in alveolar type II cell proliferation in vivo.

To determine whether rhKGF stimulated type II cell proliferation during hyperoxia, rats were given either PBS or $5 \mathrm{mg} /$ $\mathrm{kg}$ rhKGF and exposed to hyperoxia for $48 \mathrm{~h}$. The type II cell labeling index was $12.7 \pm 3.0 \%$ in the rhKGF-treated animals and $5.0 \pm 2.4 \%$ in the PBS-treated animals. Therefore, intratracheal administration of rhKGF induced alveolar type II cell proliferation even with hyperoxia exposure, although the response was not as robust as that observed when animals were maintained in room air.

rhKGF administration decreases hyperoxia-induced mortality. To determine the effect of administration of $5 \mathrm{mg} / \mathrm{kg}$ rhKGF on hyperoxia-induced lung injury, rats were treated by intratracheal instillation and exposed to hyperoxia for up to 120 h. At necropsy after $120 \mathrm{~h}$ of hyperoxia exposure, the lungs of rhKGF-treated animals appeared grossly normal with few scattered areas of punctate hemorrhage on the pleural surface compared with the grossly hemorrhagic lungs of untreated rats dying between 55 and $80 \mathrm{~h}$ of hyperoxia exposure. None of the animals surviving $120 \mathrm{~h}$ of hyperoxia exposure had fluid within the pleural space, whereas pleural effusions were noted in all the animals that died during hyperoxia exposure. Histopathologically, the lungs of untreated animals demonstrated large areas of hemorrhage and interstitial edema (Fig. $3 \mathrm{~A}$ ). The intraalveolar space contained red blood cells, inflammatory cells, and proteinaceous exudate. In contrast, there was no intraalveolar exudate and minimal evidence of hemorrhage in the lungs of the animals treated with rhKGF who survived for $120 \mathrm{~h}$ in hyperoxia (Fig. $3 \mathrm{~B}$ ).

rhKGF at doses of 1 and $5 \mathrm{mg} / \mathrm{kg}$ significantly decreased hyperoxia-induced mortality $(P<0.001$, for both doses) whereas survival for animals treated with $0.1 \mathrm{mg} / \mathrm{kg}$ rhKGF was not significantly different from either untreated rats or animals treated with heat-denatured $\operatorname{rhKGF}(P=0.32$ and $P=0.44$, respectively) (Fig. 4).

Antioxidant enzyme assays. To determine whether rhKGFinduced survival during hyperoxia exposure was mediated by an induction of whole lung antioxidant enzyme activity, rats were treated with either $5 \mathrm{mg} / \mathrm{kg}$ rhKGF or PBS and exposed to room air or hyperoxia for $48 \mathrm{~h}$ and whole lung enzyme activity was measured. rhKGF treatment did not affect whole lung specific catalase activity either after room air or hyperoxia exposure (Fig. $5 \mathrm{~A}$ ). After room air exposure, total SOD and Mn SOD activities were decreased in the rhKGF-treated animals compared with the PBS-treated group $(P<0.01$ and $P<0.02$, respectively) but there were no significant differences after hyperoxia exposure (Fig. $5 \mathrm{~B}$ ). In PBS-treated animals, there was a significant decrease in whole lung specific Mn SOD activity from $2.03 \pm 0.14$ to $1.27 \pm 0.18 \mathrm{U} / \mathrm{mg}$ protein after hyperoxia exposure $(P<0.02)$ whereas, in the rhKGF-treated animals, there was no significant difference between room air and hyperoxia exposed animals, $1.36 \pm 0.15$ vs. $1.02 \pm 0.27 \mathrm{U} / \mathrm{mg}$ protein, respectively $(P=0.33)$. Thus, based upon these studies, intratracheal rhKGF instillation did not increase whole lung specific activity of these antioxidant enzymes.

\section{Discussion}

In this report we demonstrated that rhKGF instilled into the trachea was distributed distally into the lung parenchyma and localized to alveolar epithelial cells and alveolar macrophages.
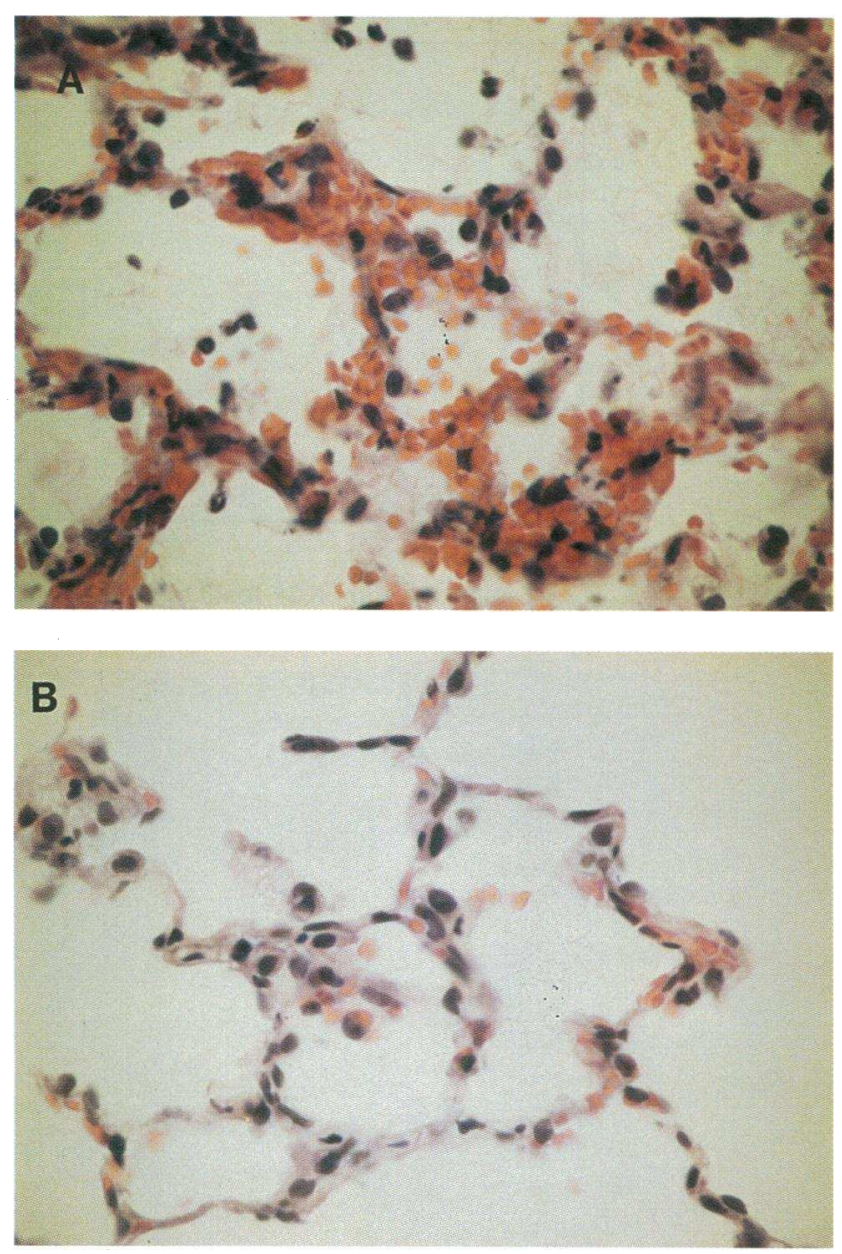

Figure 3. (A) Micrograph of a lung tissue section from a rat dying of hyperoxia-induced lung damage demonstrating widening of the alveolar septae and intraalveolar hemorrhage, exudate, and inflammatory cells (hematoxylin and eosin stain, original magnification of 400). (B) In rats that were treated with $5 \mathrm{mg} / \mathrm{kg} \mathrm{KGF}$ by intratracheal instillation and survived $120 \mathrm{~h}$ of hyperoxia exposure, the alveolar parenchyma appeared normal and there was only minimal intraalveolar hemorrhage and no exudate (hematoxylin and eosin stain, original magnification of 400).

rhKGF induced a dose- and time-dependent increase in alveolar type II cell proliferation which was quantitated by double-label immunohistochemistry. The alveolar type II cell specific labeling index reached a maximal level of $33 \pm 3 \% 48 \mathrm{~h}$ after administration of $5 \mathrm{mg} / \mathrm{kg}$ rhKGF and was 25 -fold greater than in PBStreated animals. In another series of experiments, intratracheal administration of rhKGF markedly reduced the incidence of mortality in rats exposed to hyperoxia for $5 \mathrm{~d}$. However, this protective effect could not be attributed to an increase in the activity of catalase or either total or Mn SOD because rhKGF instillation did not increase these enzyme activities in whole lung after $48 \mathrm{~h}$ of room air or hyperoxia exposure. These studies provided detailed quantitative evidence that KGF was a potent mitogen for alveolar type II cells in vivo and established that intratracheal administration of this factor could dramatically increase the survival of rats exposed to hyperoxia.

Interestingly, immunoreactive KGF was detectable only after the administration of rhKGF even though the KGF transcript is relatively abundant in normal lung tissue $(10,12,14)$. We and others have not been able to detect endogenous KGF 


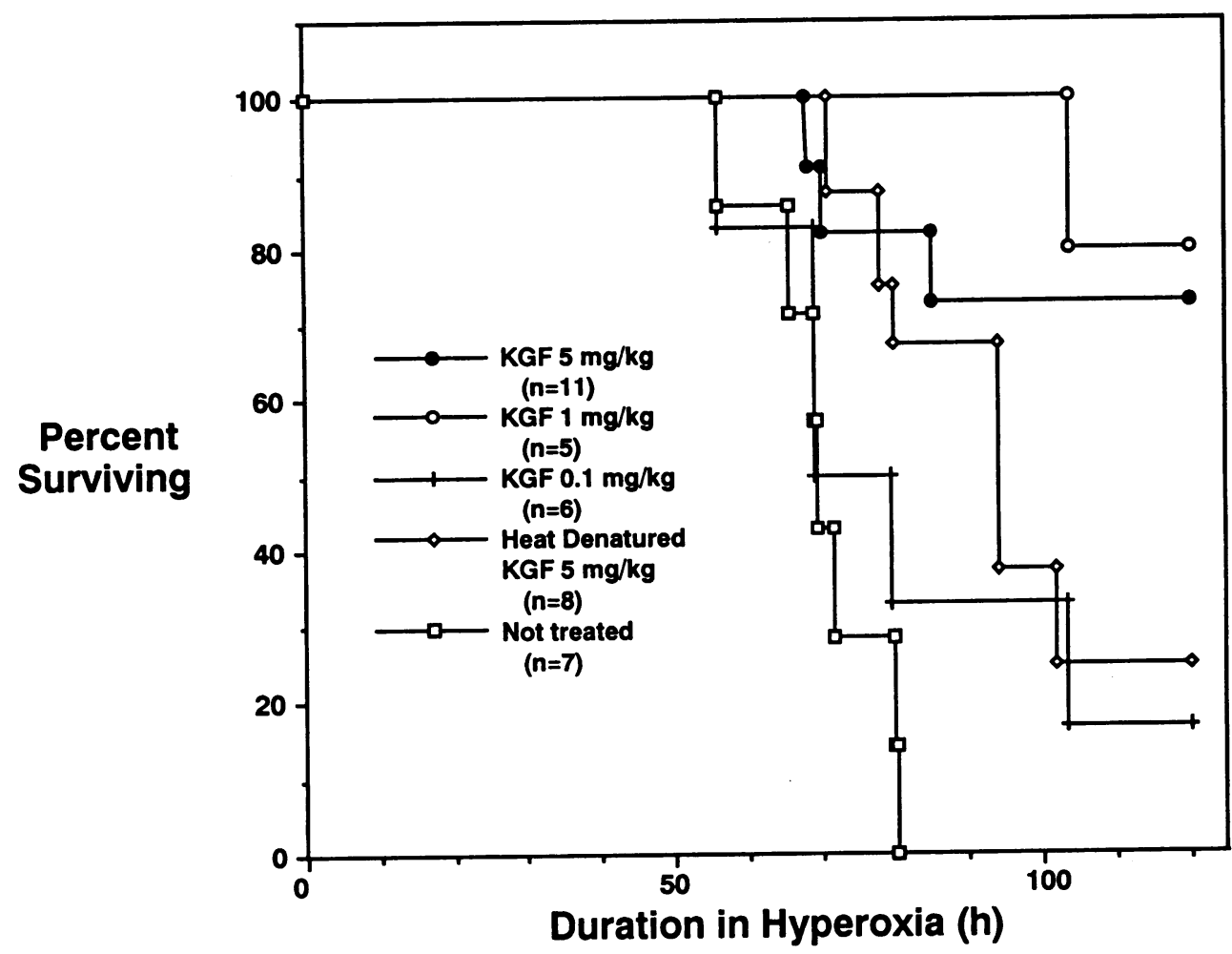

Figure 4. Intratracheal rhKGF instillation decreases hyperoxia-induced mortality in rats. Rats were treated with $0.1,1$, or $5 \mathrm{mg} / \mathrm{kg}$ $\mathrm{KGF}, 5 \mathrm{mg} / \mathrm{kg}$ heat-denatured KGF, or not treated and exposed to hyperoxia as described in Methods. Hyperoxia-induced mortality was significantly reduced by 1 and 5 $\mathrm{mg} / \mathrm{kg}$ rhKGF $(P<0.001)$. Survival for animals treated with 0.1 $\mathrm{mg} / \mathrm{kg}$ rhKGF was not significantly different from either untreated rats or animals given heatdenatured $\operatorname{rhKGF}(P=0.32$ and $P$ $=0.44$, respectively); survival for animals treated with heat-denatured rhKGF was greater than for untreated animals $(P<0.01)$. Survival data were expressed using Kaplan-Meier product limit curves and compared using the log rank test. protein in any normal tissue using currently available reagents (our unpublished observations). Low steady state levels of native KGF, sequestration on proteoglycan and consequent masking of antigenic epitopes, or protein extraction or denaturation during tissue processing may explain the inability to detect the endogenous protein by immunohistochemistry. To our knowledge, the only previous report of KGF immunohistochemical detection was in the epidermis of transgenic mice overexpressing KGF under direction of the keratin 14 promoter (41).

Immunoreactive KGF was detected in rat lung sections at the earliest time point surveyed, $6 \mathrm{~h}$ after administration, and was no longer evident $48 \mathrm{~h}$ after delivery. In contrast, although the alveolar type II cell specific labeling index was not increased in animals killed $24 \mathrm{~h}$ after rhKGF instillation, BrdUrd labeling was markedly elevated in animals killed at 48 and $72 \mathrm{~h}$. Because the rats were injected with BrdUrd $18 \mathrm{~h}$ before death, the increase in DNA synthesis, while beginning after $24 \mathrm{~h}$, was sustained for more than $54 \mathrm{~h}$ after rhKGF administration. This initial lag was probably due in part to the time required for rhKGF to contact its cell surface receptor. In addition, our previous studies (22) showed that serum was required for rhKGFinduced DNA synthesis in type II cells in vitro, suggesting that cofactor(s) may be required for rhKGF-induced alveolar type II cell proliferation in vivo. Stimulation of cellular proliferation also may necessitate overcoming negative regulatory factors such as contact inhibition that account for the quiescence of type II cells in normal adult rat lung.

The alveolar epithelial proliferative response has been used to quantify the severity of alveolar epithelial damage (42). Hyperoxia causes extensive destruction of the alveolar epithelial cell lining in monkeys (43) and in humans (44). Although some investigations have not shown significant evidence of alveolar epithelial cell damage in rats exposed to hyperoxia (45), other ultrastructural studies have demonstrated disruptions of the alveolar epithelium (46). In rats exposed to hyperoxia for a short duration and then allowed to recover in room air, there was a 2.5-fold increase in the number of type II cells determined by ultrastructural morphometric analysis (47) and a 5-fold increase in the alveolar type II cell specific labeling index (Panos, R. J., and P. M. Bak, unpublished observations). The demonstration of type II cell proliferation after limited hyperoxia exposure was consistent with the proposed reparative response of the alveolar type II cell in healing of the alveolar epithelium. Combined with our observation that rhKGF instillation stimulated a robust alveolar type II cell proliferative response, these findings provided impetus to use the rat hyperoxia model in studying the potential effects of KGF on lung injury.

Administration of rhKGF before hyperoxia exposure significantly improved survival of rats in a dose-dependent manner. Other investigators have shown that endotoxin, IL-1, or TNF also prevents hyperoxia-induced lung injury in rats (48-50). These effects were believed to be mediated by an induction in Mn SOD expression which increased $2 \mathrm{~d}$ after administration of endotoxin or either of these cytokines $(37,38,51,52)$. In our studies, rhKGF administration did not augment catalase, or total, $\mathrm{Mn}$, or $\mathrm{Cu} / \mathrm{Zn}$ SOD activity $48 \mathrm{~h}$ after intratracheal instillation and exposure to either room air or hyperoxia. Intratracheal instillation of rhKGF may affect Mn SOD activity at other time points or only within a subset of cells such that its effect might not be detected in an analysis of whole lung tissue. In addition to their stimulation of Mn SOD, IL-1 and TNF also have been shown to induce KGF mRNA expression in cultured human fibroblasts $(53,54)$. Thus, the enhanced survival of rats treated with these cytokines may also have been due to elevated expression of endogenous KGF in the lung. Alternatively, it is unlikely that trace amounts of endotoxin in bacterially expressed KGF could account for the increase in survival that we observed. Analysis of the recombinant protein preparation showed no evidence of endotoxin (Simonet, W., unpublished data), and the decreased survival of animals treated with boiled rhKGF 

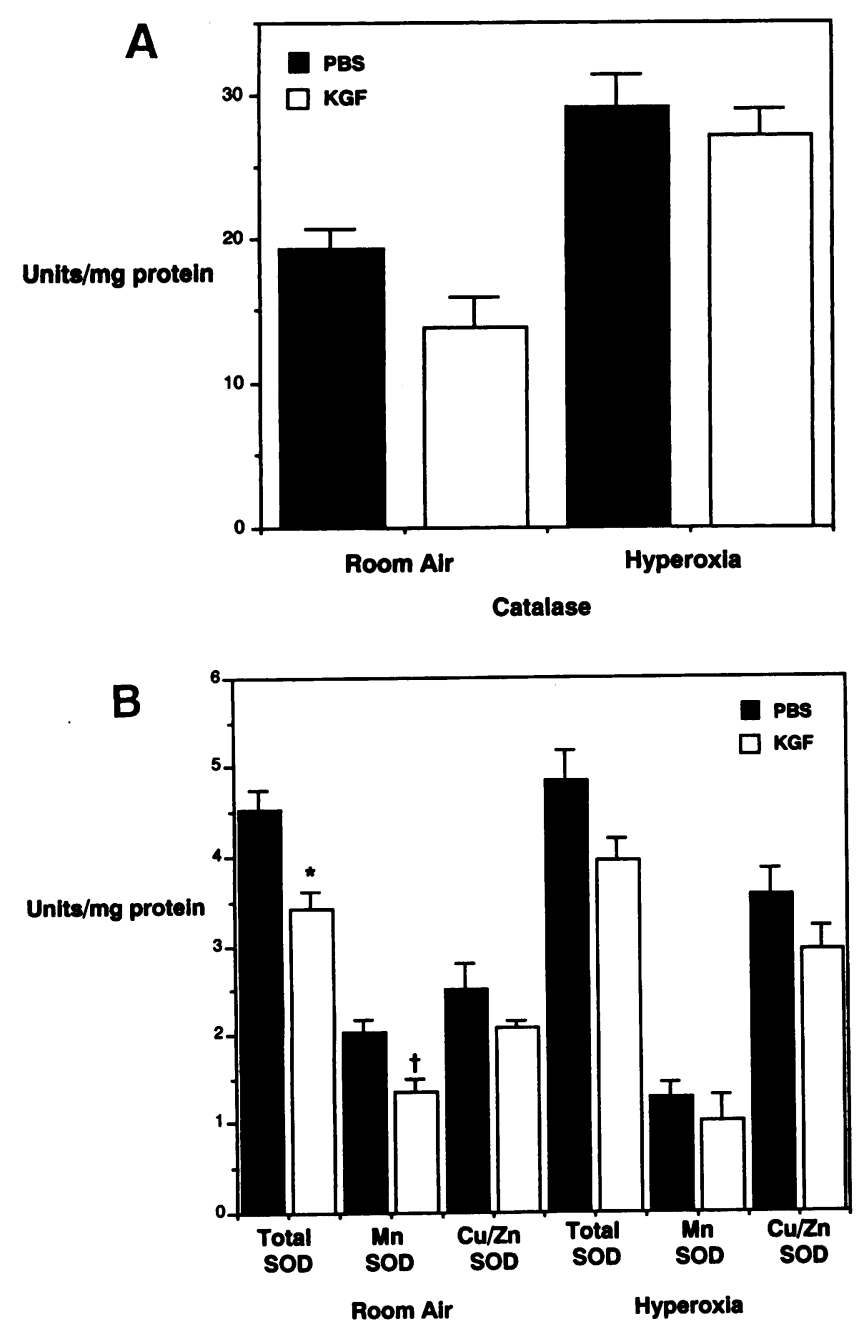

Figure 5. Intratracheal rhKGF instillation does not increase whole lung specific antioxidant enzyme activities. Groups of four rats received either $5 \mathrm{mg} / \mathrm{kg}$ rhKGF or PBS and were exposed to either room air or hyperoxia for $48 \mathrm{~h}$. Whole lung antioxidant levels were measured as described in Methods. $(A)$ There was no significant difference in whole lung specific catalase activity between rhKGF-treated and PBS-treated animals after either room air or hyperoxia exposure. $(B)$ After room air exposure, total SOD and Mn SOD activities were decreased in the rhKGF-treated animals compared with the PBS-treated group ( ${ }^{*} P$ $<0.01$ and ${ }^{\dagger} P<0.02$, respectively), but there were no significant differences after hyperoxia exposure.

was consistent with heat-labile $\operatorname{KGF}(7,22,24)$ rather than heat-stable endotoxin (55) being responsible for the protective effect described in this report. Heat-denatured KGF provided partial protection against hyperoxia-induced mortality. This effect may have been due to partial renaturation of the KGF protein after intratracheal instillation, proteolytic degradation of the instilled denatured KGF into biologically active fragments, or other protective effects of the heat-treated KGF on alveolar type II cells or other cells.

We propose that type II cell proliferation induced by KGF contributed to the improvement in survival after hyperoxia exposure. Recombinant KGF administered by intratracheal instillation is a potent mitogen for alveolar type II cells in vivo. If, as proposed by Witschi $(3,5)$, healing of the alveolar epithelium requires type II cell proliferation, intratracheal administration of rhKGF could preserve alveolar epithelial continuity by accel- erating the alveolar type II cell proliferative response. In addition, replicating type II cells may be more resistant to the deleterious effects of oxygen as occurs in the neonatal rat $(56,57)$. Independent of its effect on proliferation, KGF may promote the survival of epithelial cells by upregulating the expression of molecules like bcl-2 that are thought to inhibit cell death by reducing oxidant damage (58). Preliminary experiments suggest that KGF reduced oxidant-induced DNA damage in type II cells in vitro (59). KGF may also alter the differentiated function of alveolar type II cells including the synthesis and secretion of surfactant and surfactant proteins (Panos, R. J., and P. M. Bak, unpublished observations). Furthermore, because immunoreactive KGF was detected along both the flattened and cuboidal alveolar epithelial cells after intratracheal instillation, KGF may have a direct cytoprotective effect on type I cells as well.

Endogenous KGF in the lung probably functions as a homeostatic agent to maintain or restore the alveolar epithelium after lung injury. We believe that the administration of rhKGF reinforces the activity of endogenous KGF to ensure the integrity of the alveolar epithelium through the stimulation of type II cell proliferation and, potentially, other effects on alveolar epithelial cells that would promote their survival. The directed delivery of KGF to the lungs may provide a therapeutic strategy to enhance alveolar epithelial repair during lung damage due to hyperoxia or other injurious agents.

\section{Acknowledgments}

We thank York E. Miller, MD, for the 3F9 antibody; Alfred Rademacher, $\mathrm{PhD}$, for assistance with the statistical analysis; Sharon L. Aukerman, $\mathrm{PhD}$, for assistance with the initial intratracheal rhKGF instillation experiments; James Anderson for assistance with the antioxidant enzyme assays; and Stuart A. Aaronson, MD, for encouragement and helpful comments.

This work was funded by the Department of Veterans Affairs and Amgen, Inc.

\section{References}

1. Evans, M. J., L. V. Johnson, R. J. Stephens, and G. Freeman. 1976. Cell renewal in the lungs of rats exposed to low levels of ozone. Exp. Mol. Pathol. 24:70-83.

2. Evans, M. J., L. V. Johnson, R. J. Stephens, and G. Freeman. 1976. Renewal of the terminal bronchiolar epithelium in the rat following exposure to $\mathrm{NO}_{2}$ or $\mathrm{O}_{3}$. Lab. Invest. 35:246-257.

3. Haschek, W. M., and H. P. Witschi. 1979. Pulmonary fibrosis: a possible mechanism. Toxicol. Appl. Pharmacol. 51:475-487.

4. Witschi, H. P. 1991. Role of the epithelium in lung repair. Chest. 99:22S$25 S$.

5. Witschi, H. P. 1976. Proliferation of type II alveolar cells: a review of common responses in toxic lung injury. Toxicology. 5:267-277.

6. Crouch, E. 1990. Pathobiology of pulmonary fibrosis. Am. J. Physiol. 259:L159-L184.

7. Rubin, J. S., A. M.-L. Chan, D. P. Bottaro, W. H. Burgess, W. G. Taylor, A. C. Cech, D. W. Hirschfield, J. Wong, T. Miki, P. W. Finch, and S. A. Aaronson 1991. A broad-spectrum human lung fibroblast-derived mitogen is a variant of hepatocyte growth factor. Proc. Natl. Acad. Sci. USA. 88:415-419.

8. Aaronson, S. A., D. P. Bottaro, T. Miki, D. Ron, P. W. Finch, T. P. Fleming J. Ahn, W. G. Taylor, and J. S. Rubin. 1991. Keratinocyte growth factor. A fibroblast growth factor family member with unusual target cell specificity. Ann. NY Acad. Sci. 638:62-77.

9. Miki, T., T. P. Fleming, D. P. Bottaro, J. S. Rubin, and S. A. Aaronson 1991. Expression cDNA cloning of the KGF receptor by creation of a transforming autocrine loop. Science (Wash. DC). 251:72-75.

10. Mason, I. J., F. Fuller-Pace, R. Smith, and C. Dickson. 1994. FGF-7 (keratinocyte growth factor) expression during mouse development suggests roles in myogenesis, forebrain regionalisation and epithelial-mesenchymal interactions. Mech. Dev. 45:15-30.

11. Orr-Urtreger, A., M. T. Bedford, T. Burakova, E. Arman, Y. Zimmer, A. 
Yayon, D. Givol, and P. Lonai. 1993. Developmental localization of the splicing alternatives of fibroblast growth factor receptor-2 (FGFR2). Dev. Biol. 158:475486.

12. Finch, P. W., G. R. Cunha, J. S. Rubin, J. Wong, and D. Ron. 1995. Pattern of KGF and KGFR expression during mouse fetal development suggests a role in mediating morphogenetic mesenchymal-epithelial interactions. Dev. Dyn. 203:223-240

13. Alarid, E. T., J. S. Rubin, P. Young, M. Chedid, D. Ron, S. A. Aaronson, and G. R. Cunha. 1994. Keratinocyte growth factor functions in epithelial induction during seminal vesicle development. Proc. Natl. Acad. Sci. USA. 91:10741078.

14. Ulich, T. R., E. S. Yi, K. Longmuir, S. Yin, R. Biltz, C. F. Morris, R. M. Housley, and G. F. Pierce. 1994. Keratinocyte growth factor is a growth factor for type II pneumocytes in vivo. J. Clin. Invest. 93:1298-1306.

15. Ulich, T. R., E. S. Yi, R. Cardiff, S. Yin, N. Bikhazi, C. F. Morris, and G. F. Pierce. 1994. Keratinocyte growth factor (KGF) is a growth factor for mammary epithelium in vivo. Am. J. Pathol. 144:826-868.

16. Yi, E. S., S. Yin, D. L. Harclerode, A. Bedoya, N. B. Bikhazi, C. Morris, G. Pierce, and T. R. Ulich. 1994. Keratinocyte growth factor induces pancreatic ductal epithelial proliferation. Am. J. Pathol. 145:80-85.

17. Housley, R. M., C. F. Morris, W. Boyle, B. Ring, R. Biltz, J. E. Tarpley, S. L. Aukerman, P. L. Devine, R. H. Whitehead, and G. F. Pierce. 1994. Keratinocyte growth factor induces proliferation of hepatocytes and epithelial cells throughout the rat gastrointestinal tract. J. Clin. Invest. 94:1764-1777.

18. Staiano-Coico, L., J. G. Krueger, J. S. Rubin, S. D’limi, V. P. Vallat, L. Valentino, T. Fahey III, A. Hawes, G. Kingston, M. R. Madden, et al. 1993. Human keratinocyte growth factor effects in a porcine model of epidermal wound healing. J. Exp. Med. 178:865-878.

19. Pierce, G. F., D. Yanagihara, K. Klopchin, D. M. Danilenko, E. Hsu W. C. Kenney, and C. F. Morris. 1994. Stimulation of all epithelial elements during skin regeneration by keratinocyte growth factor. J. Exp. Med. 179:831840.

20. Werner, S., H. Smola, Y. Liao, M. T. Longaker, T. Krieg, P. H. Hofschneider, and L. T. Williams. 1994. The function of KGF in morphogenesis of epithelium and reepithelialization of wounds. Science (Wash. DC). 266:819822.

21. Werner, S., K. G. Peters, M. T. Longaker, F. Fuller-Pace, M. J. Banda, and L. T. Williams. 1992. Large induction of keratinocyte growth factor expression in the dermis during wound healing. Proc. Natl. Acad. Sci. USA. 89:6896-6900.

22. Panos, R. J., J. S. Rubin, S. A. Aaronson, and R. J. Mason. 1993. Keratinocyte growth factor and hepatocyte growth factor/scatter factor are heparin-binding growth factors for alveolar type II cells in fibroblast-conditioned medium. J. Clin. Invest. 92:969-977.

23. Peters, K., S. Werner, X. Liao, S. Wert, J. Whitsett, and L. Williams. 1994. Targeted expression of a dominant negative FGF receptor blocks branching morphogenesis and epithelial differentiation of the mouse lung. EMBO (Eur. Mol. Biol. Organ.) J. 13:3296-3301.

24. Chen, B., T. Arakawa, C. F. Morris, W. C. Kenney, C. M. Wells, and C. G. Pitt. 1994. Aggregation pathway of recombinant human keratinocyte growth factor and its stabilization. Pharm. Res. 11:1581-1587.

25. Panos, R. J., A. Suwabe, C. C. Leslie, and R. J. Mason. 1990. Hypertrophic alveolar type II cells from silica treated rats are committed to DNA synthesis in vitro. Am. J. Respir. Cell Mol. Biol. 3:51-59.

26. Ron, D., D. P. Bottaro, P. W. Finch, D. Morris, J. S. Rubin, and S. A Aaronson. 1993. Expression of biologically active recombinant keratinocyte growth factor. Structure/function analysis of amino-terminal truncation mutants J. Biol. Chem. 268:2984-2988.

27. Miller, Y. E., S. R. Walker, J. S. Spencer, R. T. Kubo, and R. J. Mason. 1989. Monoclonal antibodies specific for antigens expressed by rat type II alveola epithelial and nonciliated bronchiolar cells. Exp. Lung Res. 15:635-649.

28. Merchenthaler, I., J. Stankovics, and F. Gallyas. 1989. A highly sensitive one-step method for silver intensification of the nickel-diaminobenzidine end product of peroxidase reaction. J. Histochem. Cytochem. 37:1563-1565.

29. Dobbs, L. G. 1990. Isolation and culture of alveolar type II cells. Am. J. Physiol. 258:L134-L147.

30. Panos, R. J., and R. J. Mason. 1991. Hypertrophic alveolar type II cells isolated after silica-induced lung injury are progressing through the cell cycle and maintain a commitment to DNA synthesis in primary culture. Chest. 99:27S$28 \mathrm{~S}$.

31. Smith, L. J., J. Anderson, M. Shamsuddin, and W. Hsueh. 1990. Effect of fasting on hyperoxic lung injury in mice. The role of glutathione. Am. Rev. Respir. Dis. 141:141-149.

32. Smith, L. J., M. Shamsuddin, J. Anderson, and W. Hsueh. 1988. Hyperoxic lung damage in mice: appearance and bioconversion of peptide leukotrienes. $J$. Appl. Physiol. 64:944-951.

33. Smith, L. J., E. Sommers, C. E. Hunt, and L. Pachman. 1986. Hyperoxic lung injury in mice: a possible protective role for prostacyclin. J. Lab. Clin. Med. 108:479-488

34. Smith, L. J., H. Friedman, and J. Anderson. 1988. Hyperoxic lung injury in mice: effect of neutrophil depletion and food deprivation. J. Lab. Clin. Med. 111:449-458.

35. Smith, L. J. 1985. Hyperoxic lung injury: biochemical, cellular, and morphological characterization in the mouse. J. Lab. Clin. Med. 106:269-278.

36. Lee, E. T. 1992. Statistical Methods for Survival Data Analysis. Wiley, New York. pp. 67 and 104

37. Tang, G., J. T. Berg, J. E. White, P. D. Lumb, C. Y. Lee, and M.-F. Tsan. 1994. Protection against oxygen toxicity by tracheal insufflation of endotoxin: role of Mn SOD and alveolar macrophages. Am. J. Physiol. 266:L38-L45.

38. Clerch, L. B., and D. Massaro. 1993. Tolerance of rats to hyperoxia: lung antioxidant gene expression. J. Clin. Invest. 91:499-508.

39. Lowry, O. H., N. J. Rosebraugh, A. L. Farr, and R. J. Randall. 1951. Protein measurement with the Folin phenol reagent. J. Biol. Chem. 193:265-275.

40. McCord, J. M., and I. Fridovich. 1969. Superoxide dismutase. J. Biol. Chem. 22:6049-6055.

41. Guo, L., Q. C. Yu, and E. Fuchs. 1993. Targeting expression of keratinocyte growth factor to keratinocytes elicits striking changes in epithelial differentiation in transgenic mice. EMBO (Eur. Mol. Biol. Organ.) J. 12:973-986.

42. Evans, M. J., N. P. Dekker, L. J. Cabral-Anderson, and G. Freeman. 1978. Quantitation of damage to the alveolar epithelium by means of type 2 cell proliferation. Am. Rev. Respir. Dis. 118:787-790.

43. Kapanci, Y., E. R. Weibel, H. P. Kaplan, and F. R. Robinson. 1969. Pathogenesis and reversibility of the pulmonary lesions of oxygen toxicity in monkeys. II. Ultrastructural and morphometric studies. Lab. Invest. 20:101-118.

44. Gould, V. E., R. Tosco, R. F. Wheelis, N. S. Gould, and Y. Kapanci. 1972. Oxygen pneumonitis in man: ultrastructural observations on the development of alveolar lesions. Lab. Invest. 26:499-508.

45. Crapo, J. D., B. E. Barry, H. A. Foscue, and J. Shelburne. 1980. Structural and biochemical changes in rat lungs occurring during exposures to lethal and adaptive doses of oxygen. Am. Rev. Respir. Dis. 122:123-143.

46. Kistler, G. S., P. R. B. Caldwell, and E. Weibel. 1967. Development of fine structural damage to alveolar and capillary lining cells in oxygen-poisoned rat lungs. J. Cell Biol. 32:605-628.

47. Thet, L. A., S. C. Parra, and J. D. Shelburne. 1986. Sequential changes in lung morphology during the repair of acute oxygen-induced lung injury in adult rats. Exp. Lung Res. 11:209-228.

48. White, C. W., P. Ghezzi, C. A. Dinarello, S. A. Caldwell, I. F. McMurtry, and J. E. Repine. 1987. Recombinant tumor necrosis factor/cachectin and interleukin 1 pretreatment decreases lung oxidized glutathione accumulation, lung injury, and mortality in rats exposed to hyperoxia. J. Clin. Invest. 79:1868-1873.

49. Tsan, M.-F., C. Y. Lee, and J. E. White. 1991. Interleukin-1 protects rats against oxygen toxicity. J. Appl. Physiol. 71:688-697.

50. Tsan, M.-F., J. E. White, T. A. Santana, and C. Y. Lee. 1990. Tracheal insufflation of tumor necrosis factor protects rats against oxygen toxicity. J. Appl. Physiol. 68:1211-1219.

51. Tsan, M.-F., J. E. White, C. Treanor, and J. B. Shaffer. 1990. Molecular basis for tumor necrosis factor-induced increase in pulmonary superoxide dismutase activities. Am. J. Physiol. 259:L506-L512.

52. Tsan, M.-F., and J. E. White. 1992. Kinetics of pulmonary superoxide dismutase in interleukin-1-induced oxygen-tolerant rats. Am. J. Physiol. 263:L342-L347.

53. Chedid, M., J. S. Rubin, K. G. Csaky, and S. A. Aaronson. 1994. Regulation of keratinocyte growth factor gene expression by interleukin 1. J. Biol. Chem. 269:10753-10757.

54. Brauchle, M., K. Angermeyer, G. Huebner, and S. Werner. 1994. Large induction of keratinocyte growth factor expression by serum growth factors and pro-inflammatory cytokines in cultured fibroblasts. Oncogene. 9:3199-3204.

55. Elin, R. J., and S. M. Wolff. 1973. Bacterial endotoxins. In CRC Handbook of Microbiology. A. I. Laskin and H. A. Lechevalier, editors. CRC Press, Cleveland. 215-239.

56. Frank, L., J. R. Bucher, and R. J. Roberts. 1978. Oxygen toxicity in neonatal and adult animals of various species. J. Appl. Physiol. 45:699-704.

57. Kauffman, S. L., P. H. Burri, and E. R. Weibel. 1974. The postnatal growth of the rat lung. II. Autoradiography. Anat. Rec. 180:63-76.

58. Hockenbery, D. M. Z. N. Oltvai, X.-M. Yin, C. L. Millman, and S. J. Korsmeyer. 1993. Bcl-2 functions in an antioxidant pathway to prevent apoptosis. Cell. 75:241-251.

59. Kamp, D. W., N. Pollack, M. Nadeem, and R. J. Panos. 1995. Keratinocyte growth factor attenuates hydrogen peroxide-induced DNA damage in cultured alveolar epithelial cells. J. Invest. Med. 43:246a. (Abstr.) 